\title{
In memoriam: Samuel K. Riffell (1970-2014)
}

\author{
Kevin J. Gutzwiller • Eric D. Dibble • \\ Janet Franklin
}

Received: 7 April 2015/Accepted: 10 April 2015/Published online: 30 April 2015

(C) Springer Science+Business Media Dordrecht 2015

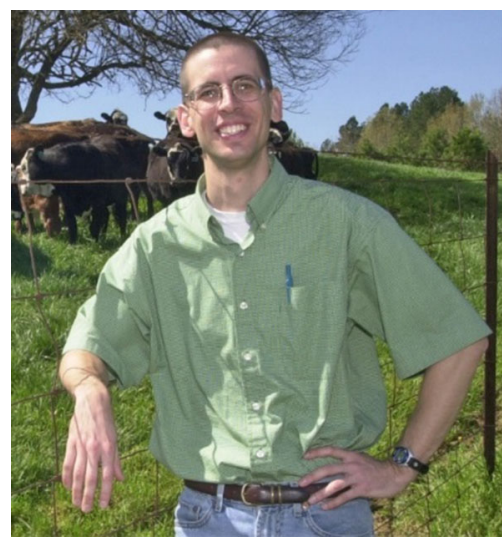

Samuel K. Riffell (Photo courtesy of Mississippi State University)

\footnotetext{
K. J. Gutzwiller $(\bowtie)$

Department of Biology, Baylor University, Waco, TX 76798, USA

e-mail: kevin_gutzwiller@baylor.edu

E. D. Dibble

Department of Wildlife, Fisheries and Aquaculture, Mississippi State University, Mississippi State, MS 39762, USA

J. Franklin

School of Geographical Sciences and Urban Planning, Arizona State University, Tempe, AZ 85287, USA
}

Samuel Keith Riffell was born on 30 June 1970 in Springfield, Ohio, and passed away on 11 August 2014 in Starkville, Mississippi. He is survived by his wife Angie and their two daughters, Abigail and Hannah. Sam contributed greatly to the discipline of landscape ecology through his work as a scientist and university professor, and by serving the U.S. Regional Chapter of the International Association for Landscape Ecology (US-IALE) in several important capacities for many years. Here we honor and celebrate Sam's enthusiasm for landscape ecological research and its application, his role in training and inspiring future landscape ecologists, and his professional service to US-IALE.

Sam was raised in Frankfort, Ohio, and attended the Frankfort public school system from grade school through high school. When not in school, Sam spent much of his youth exploring the small stream that ran near the south side of Frankfort, turning over rocks in search of different invertebrates. His fascination with small living things stuck with him as he matured and began courting Angie; she recalls that one of their first dates was spent wading a stream together overturning rocks in search of dragonfly larvae. He graduated in 1988 from Adena High School as valedictorian. After high school he pursued his passion for biology and ecology, obtaining a B.A in biology (Asbury College, 1992), an M.S. in environmental studies (Baylor University, 1994), and a Ph.D. in zoology (Michigan State University, 2000). Sam then worked as a visiting 
assistant professor at Michigan State University for a few years while he developed his teaching skills and published his doctoral and other research. In 2004, the Department of Wildlife, Fisheries and Aquaculture at Mississippi State University (MSU) hired Sam as an assistant professor to complement the Department's existing teaching and research program in AgroWildlife Ecology and to shore up the landscape ecology curriculum. Sam was promoted to associate professor with tenure at MSU in 2010 and was about to be promoted to full professor at the time of his passing.

KJG had the pleasure of working with Sam on research periodically for over 20 years. Sam made his first oral presentation of research at the 1994 US-IALE Meeting and, in his first peer-reviewed journal paper, he published this research in Landscape Ecology in 1996. This work originated from a research requirement in KJG's graduate-level Landscape Ecology course at Baylor in the fall of 1992. Students were required to develop a manuscript with significant potential for publication. Sam chose to test hypotheses about how the number of corridors that met at corridor intersections influenced the number of biotically and abiotically dispersed plant species in the intersection area. He collected data on woody species for the course project during the fall but wanted a more complete sampling of the flora for a larger analysis, so he went back to his study sites in the spring of 1993 to collect data on herbaceous species that were more detectable at that time. His work on what began as a course project did not impede his thesis research, and he completed his MS degree (under KJG) within 2 years of enrolling at Baylor. It was clear even then that Sam had fire and talent for field research and scientific publication.

His dissertation research focused on how landscape context, the cove and lobe areas of peninsulas, and habitat relationships affected birds in Great Lakes coastal wet meadows. As he developed his research program at MSU, issues of conservation in agricultural landscapes, interannual variation in bird-landscape relationships, and characterization of white-tailed deer (Odocoileus virginianus) responses to spatial scale were among the topics of his publications. More recently, he published on the responses of birds and butterflies to agricultural conservation buffers. Over the years, Sam published his landscape-related research in a variety of peer-reviewed journals, including Diversity and Distributions, Environmental
Monitoring and Assessment, Journal of Mammalogy, Journal of Wildlife Management, Landscape Ecology, Landscape Online, Oikos, and Wetlands. Sam also advanced the discipline of landscape ecology by contributing many formal reviews of Landscape Ecology manuscripts. As one coordinating editor who solicited some of those reviews, KJG recalls that Sam expected quantitative rigor, and his comments were clear, tactful, and often outlined for authors how they could surmount an analytical problem.

KJG enjoyed collaborating with Sam for many reasons. Sam was honest about what he could contribute and whether he would be able to meet a certain deadline. If he thought he could not deliver, he would decline to get involved. Sam kept you informed of developments, so if he ran into a snag during a project, you knew it right away, and he would often have a solution to the problem by the time you contacted him to discuss how to proceed. Sam was modest about his achievements. KJG remembers congratulating him on a significant research accomplishment and hearing him chuckle "Yeah, sometimes I surprise myself." He had an enthusiasm for research that is difficult to capture in words, once quipping that after getting some current work under control he looked forward to "chasing rabbits." Conjuring up hounds baying gleefully and running full tilt through thicket and field after their quarry, this phrase was Sam's metaphor for pursuing some exciting new landscape ecology ideas or concepts that might be just beyond easy intellectual reach. Above all, Sam had integrity-he refused to let the need to acquire grants and to publish pressure him into taking shortcuts on the quality of his research, and he was careful to be forthright about how he had done his work and what his results meant.

Sam also contributed importantly to the field of landscape ecology as a professor at MSU. There he taught Ornithology, and Principles and Practices of Conservation in Agricultural Landscapes, and he developed a Wildlife Concentration for the Department as well as a new course in Landscape Ecology. During 2009-2014, he served as undergraduate coordinator, and the wisdom and foresight he shared in this role proved critical to the success of the Department's undergraduate program.

Shortly after Sam passed away, EDD had the difficult task of sorting through his office and organizing his belongings. While doing so, he took 
the liberty to peel off a small piece of paper that Sam had taped in a place on his office door where students who entered his office would easily notice it. The paper read "Working hard is a skill you have to nurture." EDD did not know whether these words were Sam's or from someone else, but they epitomized Sam's mentoring approach. He let his students know that it requires hard work to be successful, but at the same time he was quick to explain that work was a behavioral skill that required practice, and that he was there to help them do just that. Sam's small strip of paper with the quote is now taped strategically over EDD's desk.

Examples of comments from a few of Sam's former students reveal his skill and dedication as an educator and mentor.

Sam's strength as a mentor and a teacher was his knack for quickly assessing the ability and learning style of a student when working with them in a one-on-one situation. If a student would learn best by reading the material on their own, then Sam would hand over a book on the topic, as he did with me (he handed me Turner, Gardner and O'Neill's Landscape Ecology in Theory and Practice). If a student needed a hands-on approach, then that is what he would use. He engaged a student's understanding by filtering the material through their own interests, in my case statistical modeling. On my comprehensive exams for my Ph.D., Sam handed me a paper on ecological and perceptual traps on the landscape, and told me to refit the models using data I had collected. Sam was able to efficiently get me to understand ecological and perceptual traps in a way that was commensurate with my learning style and experience without directly teaching at all. - Dr. Zackary Loman, MSU.

I remember the day I defended my dissertation, I felt very nervous before beginning my presentation and couldn't get those butterflies to calm down. I happened to look behind me and saw Dr. Riffell. He smiled, winked, and gave me a nod of encouragement. That small gesture gave me the confidence boost I needed to calm down and power through the stressful day. After graduation, we talked often about my job opportunities and worked on publishing the chapters of my dissertation. He was even in attendance the day I got married. He was always so proud of my accomplishments that it makes me sad that I never got the chance to tell him that I finally got my dream job as an assistant professor of wildlife habitat management. I'm confident, though, that he's looking down giving me the wink and nod of approval. - Dr. Heidi Adams, Assistant Professor of Wildlife Habitat Management, Louisiana Tech University.

I was Sam's first doctoral student. With his excellent mentoring in landscape ecology, he taught me the importance of observation, critical thinking, and knowledge of the life histories of even the smallest animals in a particular ecosystem. The days I spent with him in the field and in the lab were the brightest of my graduate school days. One I will never forget was during a field outing with Sam and his daughters. He excitedly retrieved several butterfly nets from the trunk of his car and started to run around with his two girls trying to net butterflies and dragonflies. With a big smile he turned to me and said "It is always wise to keep a butterfly net in the trunk of one's car." - Dr. Jolie Goldenetz Dollar, Agroforestry Consultant, Xerces Society.

Sam's contributions to landscape ecology extended beyond his research, teaching and mentoring. He also contributed strongly to our discipline through his professional service to US-IALE, serving in several capacities, and in some for many years. In 1996, Sam told KJG that he thought that the Executive Committee should have a student representative. KJG happened to be on the Executive Committee at the time and invited Sam to briefly present his ideas to the Committee at an upcoming meeting. We do not think that any student had ever attended an Executive Committee meeting before, but after Sam expressed his thoughts, history was made. Recognizing the wisdom in Sam's remarks, the Committee agreed with his idea, and it was not long before Sam — as the first student representativewas defining and taking on the duties of this new position. During his tenure (1997-1999), he helped to expand and solidify the student focus of US-IALE that persists so strongly to this day.

Sam chaired the Foreign Scholar Travel Awards Committee during 2001-2009 and was a member of the Committee until his passing. He "was always willing to answer questions and provide insight into 
the corporate memory of the committee" remembers Kathy Vigness-Raposa, the current Chair of this committee. Sam was elected Councilor-at-Large for 2006-2008, chaired the Journal Promotion Committee (2006-2007), and was a member of the Nominating Committee (2006-2014), a reviewer for conference abstracts (2005-2007), a student presentation judge (2005-2009), and a member of the Local Planning Committee for the 1998 US-IALE Meeting. Considering the numerous professional responsibilities of a young faculty member, it is difficult to imagine how he served US-IALE in so many ways for so many years. A significant part of US-IALE's current success, especially in nurturing future landscape ecologists, is attributable to Sam's remarkable service and leadership.

Sam's colleagues at MSU valued his skills, intelligence, and the efficiency with which he worked. Most appreciated were his attitude toward work and how he unselfishly dedicated time to students and colleagues. We are grateful to have shared a small part of life with him, and it is difficult to accept that the everyday moments of interaction with Sam have ended. His career is compelling inspiration for all who wish to contribute significantly and selflessly to a discipline through their science, mentoring, and professional service. The landscape ecological and conservation communities will remember Sam as imaginative, enthusiastic, industrious, dedicated, forthright, friendly, and supportive.

Acknowledgments We thank Angie Riffell for supplying details about Sam's life and reviewing this article; Sam's mother, Janis Riffell, for clarifying facts about Sam's early life; Sam's students at Mississippi State University for sharing with us their experiences with Sam; and Peter August for advice about the paper.

Compliance with Ethical Standards The authors declare that they are in full compliance with all of the ethical standards for publishing in Landscape Ecology.

Conflict of interest The authors declare that they have no conflicts of interest. 